\title{
Herpes simplex Virus
} Esophagitis in an

\section{Immunocompetent Patient with Ebstein-Barr Virus Infection}

\author{
M. Tzouvala ${ }^{a} \quad$ A. Gagliab ${ }^{b} \quad$ N. Papantoniou ${ }^{c}$ \\ K. Triantafyllou ${ }^{\text {b }} \quad$ G. Karamanolis ${ }^{b}$ \\ ${ }^{\mathrm{a}}$ Gastroenterology Department, West Attikis GH, Agia Varvara,

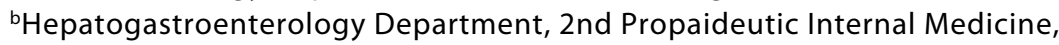 \\ 'ATTIKON' UGH, Haidari, and 'Gastroenterology Clinic, Rhodos General Hospital, \\ Rhodos, Greece
}

\section{Key Words}

Epstein-Barr virus infectious mononucleosis - Herpes simplex virus esophagitis

\begin{abstract}
Epstein-Barr virus infectious mononucleosis can cause transient immune deficiency which may predispose to reactivation of latent herpes simplex virus (HSV) infection in the immunocompetent host. We report the case of a 15-year-old male who presented with severe odynophagia and herpes labialis during the course of Epstein-Barr virus infectious mononucleosis that had been diagnosed ten days before. Esophagoscopy revealed extensive ulcerations with distinct borders and whitish exudates at the mid and distal esophagus. Polymerase chain reaction detected HSV-1 DNA in the biopsy specimens. The patient was treated with intravenous acyclovir. The symptoms resolved rapidly within 3 days, in accordance with improved endoscopic findings.
\end{abstract}

\section{Introduction}

Epstein-Barr virus infectious mononucleosis (EBV-IM) is a common infection that affects 25 to $30 \%$ of adolescents and adults up to 30 years of age [1]. EBV-IM can be complicated by streptococcal pharyngitis in $10 \%$ of cases but has not been identified as a predisposing factor for secondary viral infections [2]. Herpes simplex virus (HSV) is a rare cause of esophagitis in the immunocompetent host. We present the case of a 15-year-old male who was admitted with HSV-1 eosophagitis (HSVE) ten days after the diagnosis of EBV-IM. 


\section{Case Report}

A 15-year-old male presented with a 2-day history of severe odynophagia and malaise. Ten days before admission, the patient had visited his general practitioner because of a sore throat and fever and been diagnosed with EBV-IM. He reported no medical history of recurrent infections and he was not receiving any medication. At admission, his temperature was normal. Physical examination revealed small palpable cervical lymph nodes and a brownish exophytic lesion on his lower lip, compatible with severe manifestation of herpes labialis. Despite the severity of the lip lesion, examination of the oral cavity and throat did not reveal any abnormal findings. Erythrocyte sedimentation rate was $50 \mathrm{~mm} / \mathrm{h}$ while the rest of the routine laboratory tests were normal, including blood and differential count. Immunoglobulin quantitation was normal, while T cell and B cell count were not performed. Esophagoscopy revealed confluent linear and roundish ulcerations in the mid and distal esophagus, which had distinct borders and were covered by whitish exudates. The mucosa among the ulcerations was friable and hemorrhagic (fig. 1). Multiple biopsies were obtained from the edge of the ulcers. Histopathology showed acute severe inflammation of the squamous epithelium with no viral inclusion bodies. The diagnosis was made by detecting HSV-1 DNA with polymerase chain reaction (PCR) in the biopsy specimens. Serology revealed elevated IgM and IgG antibodies against the viral capsid antibody of the EBV which confirmed recent infection with the virus. The IgM antibody (ELISA) against HSV-1 was negative while the IgG was positive. Human immunodeficiency virus serology was negative.

Due to the severity of the odynophagia and the endoscopic appearance, acyclovir was administered intravenously ( $5 \mathrm{mg} / \mathrm{kg}$ three times daily) and clinical improvement was rapidly observed. Three days after acyclovir administration, second-look esophagoscopy showed a marked improvement of the esophageal lesions; the depth and the width of the lesions were significantly reduced, and normal mucosa could be seen among the ulcerations (ig. 2). The patient had an uneventful recovery and one year later he was in good health. His laboratory tests were within normal limits.

\section{Discussion}

To our knowledge this is the first case of EBV-IM in a previously healthy individual complicated by HSVE. Although the underlying mechanism for this complication is unclear, we hypothesize that immune deficiency during acute EBV infection might lead to reactivation of HSV [3]. In acute EBV infection the infected B cells produce antibodies against the host cells and virus proteins. CD8+ cytotoxic T cells are responsible for suppressing the replication of the virus. The population of the CD8+ cytotoxic T cells expands, inverting the CD4+/CD8+ ratio, and almost half of them are directed against the virus [4]. Junker et al. [5] showed that EBV affects both B and T lymphocytes and causes broad-based transient immune deficiency in patients with uncomplicated infection. The impaired B cells produce deficient quantities of antibodies while T suppressor cells inhibit antibody production $[5,6]$. HSV proliferation causes infections that are also controlled by CD8+ T cells.

Affinity of HSV to squamous epithelia predisposes the esophagus to be affected [7]. HSVE in an immunocompetent host can present either as a primary or recurrent infection. Gingivostomatitis with bilateral oropharyngeal lesions, ulcerations and erythema of the gingiva, buccal mucosa and tongue, lymphadenopathy and fever are usual manifestations of primary infection, while unilateral oropharyngeal lesions and cold sores suggest secondary infection [8].The HSV infection in our case is considered recurrent because of the IgG seropositivity at admission and the cold sores (herpes labialis). Herpes labialis appears in 20 to $40 \%$ of seropositive individuals and has been reported to present with HSVE in another two cases [8-10]. It seems that HSV primary infection in young healthy adults causes more severe symptoms compared to HSV infection in childhood. Improved hygiene is one of the reasons for the delayed contact with the virus.

HSV causes similar endoscopic findings in the esophagus of both immunocompetent and immunocompromised patients. Located usually in the mid-distal esophagus, the 
usual appearance of HSVE is of friable, hemorrhagic mucosa with ulcerations of various depth and length that coalesce. Biopsies from the edge of the ulcers are the appropriate specimen for detecting the virus. Inclusion viral bodies cannot be found in half of the cases [11] and PCR has lately been used for detecting virus DNA in the biopsy specimens. PCR is a more sensitive, cost-effective and rapid method compared to the viral cultures and enzyme immunoassay, providing results within a few hours $[12,13]$. Serology has restricted diagnostic value since $90 \%$ of healthy teenagers are seropositive. Only seroconversion from negative to positive HSV antibody can provide information of recent infection. Only $5 \%$ of the seropositive patients who undergo reactivation of the virus have a four-fold rise in titre of the antibody to HSV [14]. Although infection in the immunocompetent host is self-limited, in the presence of immunodeficiency, marked clinical symptoms, or complicated course treatment with the guanosine analogue acyclovir shortens the duration of the symptoms and esophageal lesions. Improvement of odynophagia is expected within $24-72 \mathrm{~h}$ and early onset of therapy is believed to speed up symptom resolution [15]. However, whether improvement of the symptoms is the result of acyclovir or of the natural course of the disease is an issue of debate, due to the low incidence of HSVE in immunocompetent patients.

In conclusion, we report a young patient who presented with HSVE ten days after the diagnosis of EBV-IM. The transient immune deficiency caused by EBV-IM is believed to be the predisposing factor for the reactivation of HSV. In view of the rarity of this condition and the low sensitivity of macroscopic assessment, a high index of suspicion is certainly necessary.

Fig. 1. Endoscopic image at admission: confluent linear and roundish ulcerations in the esophagus with distinct borders and coverage of whitish exudates.

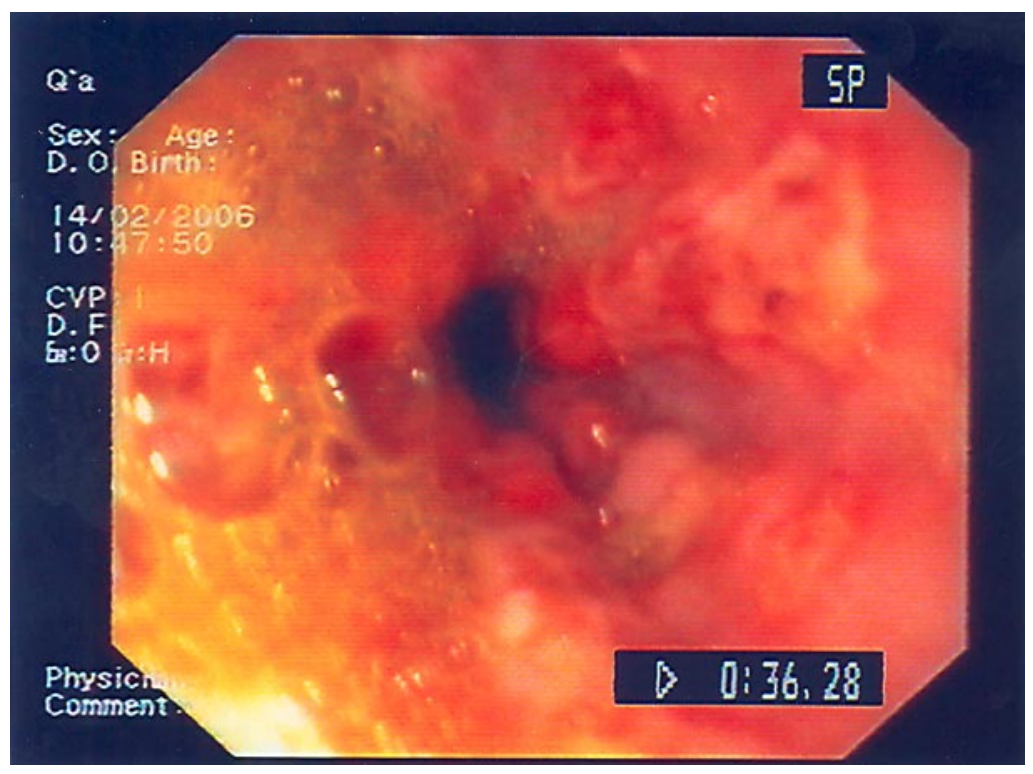


Fig. 2. Endoscopic image 3 days after acyclovir administration: depth and width of the lesions are significantly reduced and normal mucosa appears among the ulcerations.

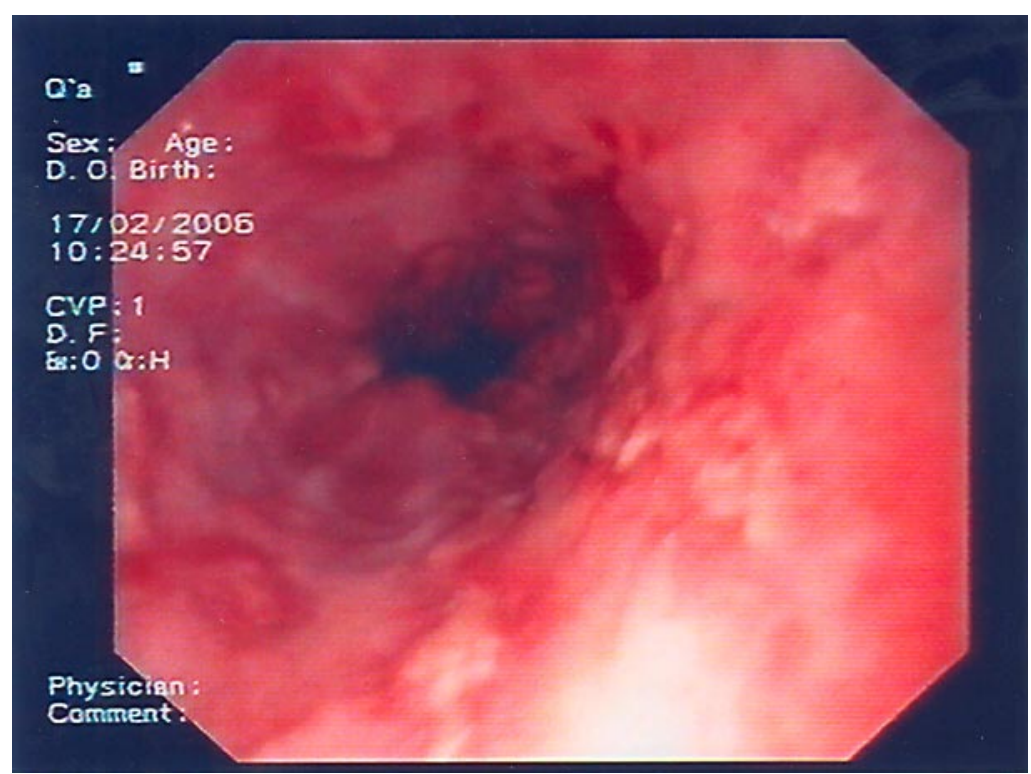




\section{References}

1 Halee TJ, Evans AS, Niederman JC, et al: Infectious mononucleosis at United States Military Academy. A prospective study of a single class over four years. Yale J Biol Med 1974;47:182-195.

2 Axelrod P, Finestone AJ: Infectious mononucleosis in older adults. Am Fam Physician 1990;42:1599-1606.

3 Pamuk OM, Pamuk GE, Celik AF, et al: Herpes simplex virus esophagitis in an immunocompetent host with sepsis. Am J Gastroenterol 2001;96:2264-2266.

4 Cohen JI: Epstein-Barr virus and the immune system. Hide and seek. JAMA 1997;278:510-513.

5 Junker AK, Ochs HD, Clark EA, et al: Transient immune deficiency in patients with acute Epstein-Barr virus infection. Clin Immunol Immunopathol 1986;40:436-446.

6 Bowen TJ, Wedgwood RJ, Ochs HD, et al: Transient immunodeficiency during asymptomatic Epstein-Barr virus infection. Pediatrics 1983;71:964-967.

7 Becker K, Lübke HJ, Borchard F, Häussinger D: Inflammatory esophageal diseases caused by herpes simplex virus infections - overview and report of 15 personal cases. Z Gastroenterol 1996;34:286-295.

8 Kamayama T, Sujaku C, Yamamoto S, et al: Shedding of herpes simplex virus type 1 into saliva. J Oral Pathol 1998;17:478-481.

9 Pazin GJ: Herpes simplex esophagitis after trigeminal nerve surgery. Gastroenterology 1978;74:741-743.

10 Springer DJ, DaCosta LR, Beck IT: A syndrome of acute self-limiting ulcerative esophagitis in young adults probably due to herpes simplex virus. Dig Dis Sci 1979;24:535-539.

11 Ramanathan J, Rammouni M, Baran J, et al: Herpes simplex virus esophagitis in the immunocompetent host: an overview. Am J Gastroenterol 2000;95:21712176 .

12 Nahass GT, Goldstein BA, Zhu WY, et al: Comparison of Tzanck smear, viral culture and DNA diagnostic methods in detection of herpes simplex and varicella-zoster infection. JAMA 1992;268:2541-2544.

13 Lee B, Caddy G: A rare cause of dysphagia: herpes simplex esophagitis. World J Gastroenterol 2007;13:2756-2757.

14 Corey L: Herpes simplex viruses; in: Harrison's Principles of Internal medicine, ed 15. McGraw Hill, New York, 2001, pp 1100-1106.

15 Kurahara K, Aoyagi K, Nakamura S, et al: Treatment of herpes simplex esophagitis in an immunocompetent patient with intravenous acyclovir. Am J Gastroenterol 1998;93:2239-2240. 